\title{
Mudanças e permanências: um olhar antropológico sobre as relações de gênero na cultura brasileira
}

De perto ninguém é normal: estudos sobre corpo, sexualidade, gênero e desvio na cultura brasileira.

\section{GODENBERG, Mirian.}

2. ed. Rio de Ja neiro: Record, 2004. v. 1. $189 \mathrm{p}$.

O livro De perto ninguém é normal, de Mirian Goldenberg, é fruto da compilação de pesquisas dos últimos dez anos realiza das pela autora, que perpassa temas abordados por ela desde seu doutoramento em Antropologia Social. Escrito de forma leve e informal, a obra possibilita a o leitor pensar sobre as relações de gênero, comportamentos tidos como desviantes ou transgressores, corpo, sexualidade e os modelos de relações conjuga is que circula $m$ na sociedade brasileira a tua Imente.

Estabelecendo uma estreita relação entre teoria e pesquisa de campo (questionários e entrevistas em profundidade), Goldenberg pesquisa ascamadasmédiasurbanascariocase discorre sobre a importância de pesquisas antropológicasquando o próprio pesquisadoré o nativo de sua pesquisa. Em outras palavras, quando o outro compartilha muitos dos valores, hábitos e costumes do próprio pesquisador, não existindo a distância geográfica, lingüística e cultural, sendo a única distância existente aquela produzida pela forma de olhamos o outro ou a nós mesmos. Destaca ainda a importância de se perceberque "compreendermelhoro outro ajuda não só a compreendermelhora nós mesmos mas também a revelar aspectos obscuros, ocultos, silencia dos de nossas próprias vidas e da cultura na qual estamos inseridos" (p. 30-31). 
O capítulo "O corpo cativo: sedução e escravidão feminina" instiga a reflexão sobre o a tual culto ao corpo e à aparência instaurada na cultura brasileira a tra vés da a presentação dos resulta dos de diferentes pesquisas. Goldenberg inc rementa a discussão a partir dascontribuições de Marcel Mauss sobre as técnicascomora is, com resultados e discussão de suas pesquisas a respeito do papel do corpo na cultura carioca, e de comentários de outros autores, como a psicanalista inglesa Susie Orbach e Naomi Wolf, sobre corpo e sexualidade. Afirmando que as mulheres estão a prisiona dasa os seus corpos, que nã o a lmejam ma is o prazer, a liberda de, ma s sim a perfeição estética moldada pelas mãos de cirurgiões plásticos, a a utora critica a excessiva valoriza ção do corpo, o aprisionamento aos padrões de beleza e suasconseqüênciasafetivosexuais, e discute o que denomina de papéis de gênero.

Gênero é definido e utilizado pela autora como um conceito que serve para "desnatura liza os pa péis e as identida des a tribuídos a o homem e à mulher. Assim, diferencio o sexo (dimensão biológica dos seres humanos) do gênero (uma escolha cultural, arbitrária, um produto social e histó ric o )" (p. 7). A tendência teóricoepistemológica estrutural presente neste trabalho c a ra c teriza-se qua ndo asposiçõesoc upa daspor homens e mulheres aparecem ainda muito invariantes e universalizadas. No entanto, a expressão papéis de gênero utilizada por Goldenberg remete à idéia de função de homem e função de mulher, justamente com a qual o conceito gênero visa romper ao substituir a expressão papéis sexuais.

Ao disc utir as representa ções de gênero, a valoriza ção da sexualidade e os diferentes usos do corpo entre jovens de camadas médias cariocas, a autora mostra que há mudanças e perma nências do comportamento sexual desses jovens. Entre as mudanças, pode-se citarque a diferença entre os gêneros, quando se trata da primeira relação sexual, vem diminuindo, pois, como já explicitado em diferentes pesquisas, a idade de iniciação sexual de meninose meninas é aproximada. Outra mudança é que asmeninas que afirmaram ser virgens sentem-se como desviantes, rompendo com a visão ma is tradicional que prega a virgindade antes do matrimônio. Entre as permanências, aparece a dupla moral sexual que incentiva a multiplicidade de parceiros para os homens e restringe os parceiros sexua is para as mulheres. Essa dupla moral que norteia o comportamento sexual e preventivo dos jovens brasileiros é fruto da coexistência de valores mais tradicionais e modernos na nossa cultura. Assim, os jovens investigados demonstram que transitam entre os diversos valores que moldam seus discursos e práticas.

Identific ando a tão exalta da valorização do corpo magro da mulher e a importância da altura, virilidade e potência para os homens, Goldenberg cita Pierre Bourdieu para afimarque não só as mulheres estão presas ao seu corpo real que é diferente do ideal, mas também os homens vistos como domina ntes sofrem, pois as exigênciasa respeito de um detemina do modelo de corpo recaem também sobre eles, que se preocupam com a força física, virilidade, potência, altura e com o tamanho do pênis.

A autora destaca uma temática muito abordada dentro do campo do gênero, que é a questão do corpo. Mostrando que esse corpo também é construído socialmente, não sendo visto como algo biológico dado de antemão, os resulta dos de pesquisa smostram o que J oan Scott ressalta a o afirmar que "o corpo tem também uma história. E portanto, toma-se o corpo para encontraralgo, para legitimara lguma coisa. Sim, nós temosum corpo, maso uso do corpo, a idéia do corpo, o conc eito do corpo, o status do corpo, isto depende do contexto social e históric $0^{\prime \prime}$. Goldenberg em suas a nálises ressa lta o lugarque - corpo ocupa para as camadas médias cariocas, afirmando que o corpo feminino valoriza do a tualmente é fruto do modelo de corpo veiculado pela mídia, o corpo magro.

A convivência de valorese comportamentos tradicionais e modemos aparece também ao discutir a multiplicidade e a flexibilização dos arranjos conjugais. A coexistência de antigos e novos modelos de conjugalidade gera uma ressignific ação dos a rra njos conjugais, que segundo Goldenberg, rompe com a dualidade tradicional $X$ moderno. Os resultados de uma pesquisa realizada pela autora mostram que ainda há o ideal do amor romântico tanto para homens quanto para mulheres, porém, mais enfatiza do porelas. No entanto, a o mesmo tempo são citados a spectos como individuali-dade, privacidade e liberdade, valores estes mais contemporâneos e enfatizados pelos homens, que vão de encontro com os ideais do amor romântico, como por exemplo o de doação.

No capítulo dedicado à temática dos (re)a rranjosconjuga is percebem-se a proxima ções e distanciamentos nos discursos de homens e mulheres investigados, o que possibilita pensar nas rela ções de gênero. As a proxima ções estão relacionadas a o compartilhamento do ideal de 
amor romântico, à importância do respeito nas relações, e os distanciamentos se referem, principalmente, às diferentes concepções de infidelidade descritas por homens e mulheres.

Em relação à infidelidade, resultados apontam que a mulherque trai se vê como vítima, pois a firma tra ir porfalta de a tenção, ca rinho do parceiro. Já o homem justifica a tra ição a través do instinto masculino, por 'ga linhagem', tesão, sendo este último sempre visto como o culpado da tra ição, tanto delesquanto delas. A conclusão a que a autora chega após a análise das respostas femininas é que a mulher ao trair "no máximo reage à dominação masculina" (p. 92), e por isso se vêem como vítimas, o que contribu para a crista lização de uma vitimizaçãa o feminina.

Continuando a discussão sobre a multip licidade de a rranjos conjuga is, a autora faz a análise da novela Laços de família exibida pela Rede Globo de Televisão no ano 2000 Goldenberg a firma que o modelo tradic ional de família a inda é hegemônic o e os que vivem outros tipos de a ranjos conjug a is sentem-se desviantes. A novela serviu para análise, pois apresentou indícios de dec línio da família nuclear, tradiciona (pai + mãe + filhos), pois mostrava vários modelos de novas conjugalidades. Novamente a convivência dos padrões tradiciona is de comporta mento com os ma is modemosa parece como resultado da análise, pois, apesar da multip lic ida de de a ra njos conjug a is presentes no decorrer de toda a novela, ao final da trama todos os temas tabus desaparecem e os visto como desviantes (prostituta, mãe solteira) são norma tiza dos a tra vés do ma trimônio.

No capítulo intitula do "Mulherese militantes" é desc rita a trajetória daquelas que partic iparam da luta polític a brasileira, para compreender a posição e atuação feminina em um contexto representado principalmente por homens e a nalisar como se constrói a identidade da mulher militante. Através da leitura das biografias de mulheres como Olga Benário e Maria Prestes, entre outras, Goldenberg é uma mulher que escreve uma histónia sobre mulheres, rompendo com a tradição da história dos homens escritas pelos homens.

O comportamento de muitas dessas mulheres militantes poderia ser compreendido, no contexto sócio-histórico em que estavam inseridas, como desvia nte, pois ela sextra pola ram o mundo privado e alcançaram, ganharam notoriedade no mundo público, caracterizado como o mundo dos homens. A conquista de uma posição importante neste "mundo dos homens" é ainda mais valorizada, pois, apesar do machismo existente elas, conseguiram superara posição de inferioridade.

No último capítulo do livro, chamado "Bandido ou herói", a autora aborda as representações existentes em tomo da imagem de Carlos Marighella, militante comunista, um revolucionário brasileiro preso e torturado por diversas vezes pela ditadura militar até sua morte. Goldenberg descreve detalhadamente versões da morte de Carlos Marighella e a ponta as representações que surgem, como a de bandido, assassino, e herói, corajoso e valente. Nesse capítulo a autora rompe com a continuidade do texto, distanciando-se dos temas abordados anteriormente, e ressaltando, dessa vez, a história de um homem que lutava pela liberdade.

Colaborando com a produção aca dêmica nacional e dando visibilidade aos estudos de gênero ao publicar uma obra de fácil compreensão e maior acesso à população, a autora ressalta aspemanênciase mudanças das relações de gênero, dos (re)arranjos conjugais, sendo, muitas vezes, a mudança compreendida como transgressora. Com uma grande variedade de temas pesquisados, a obra está repleta de interessantes conclusões, porém, com tamanha diversidade de assuntos, ficou faltando um aprofundamento teórico que possibilitasse ma iores avanços nas disc ussões. Enfatizando o aspecto relacional e os múltiplos fatores que influenciam o constituir-se homem e mulher na sociedade brasileira, o livro, a inda assim, mostra que, a tra vés do exercício de estranharo que nos é familiar, é possível compreender melhor nós mesmos e nossa cultura, com seus discursos e práticas, auxiliando a construção de um olhar ma is crític o sobre nossa sociedade.

\section{Notas}

${ }^{1}$ Miriam GROSSI, Maria Luiza HEILBORN e Camen RIAL 1998, p. 124

${ }^{2} \mathrm{~A}$ autora iniciou seus estudos sobre a construção social da identidade feminina no Brasil em 1988 ao investigar "Mulheres \& Milita ntes" (GOLDENBERG, 1997).

\section{Referências bibliográficas}

GOLDENBERG, Mirian. "Mulheres \& Militantes". Revista Estudos Feministas, v. 1, n. 2, p. 349364, 1997.

GROSSI, Miriam; HEILBORN, Maria Luiza; RIAL, Carmen. "Entrevista com Joan W. Scott". Revista Estudos Feministas, v. 6, n. 1, p.114124,1998

Mariana Barreto Vavassori Universidade Federal de Santa Catarina 